\title{
Below-Background lonizing Radiation as an Environmental Cue for Bacteria
}

\author{
Hugo Castillo* and Geoffrey B. Smith \\ Department of Biology, New Mexico State University, Las Cruces, NM, USA
}

All organisms on earth grow under the influence of a natural and relatively constant dose of ionizing radiation referred to as background radiation, and so cells have different mechanisms to prevent the accumulation of damage caused by its different components. However, current knowledge of the deleterious effects of radiation on cells is based on the exposure to acute and high or to chronic, above background doses

OPEN ACCESS

Edited by:

Michael Sauer,

University of Natural Resources and Life Sciences, Vienna, Austria

Reviewed by: Linda Christine Deveaux,

South Dakota School of Mines and Technology, USA

Alexandros G. Georgakilas,

National Technical University of Athens, Greece

Mario Xavier Ruiz-González, Secretaría de Educación Superior, Ciencia, Tecnología e Innovación and

Universidad Técnica Particular de Loja, Ecuador

*Correspondence:

Hugo Castillo

hac141@nmsu.edu

Specialty section:

This article was submitted to Microbial Physiology and Metabolism,

a section of the journal

Frontiers in Microbiology

Received: 24 October 2016

Accepted: 24 January 2017

Published: 14 February 2017

Citation:

Castillo $H$ and Smith GB (2017) Below-Background lonizing Radiation as an Environmental Cue for Bacteria.

Front. Microbiol. 8:177.

doi: 10.3389/fmicb.2017.00177 of radiation and therefore is not appropriate to explain the cellular and biochemical mechanisms that cells employ to sense and respond to chronic below-background levels. Studies at below-background radiation doses can provide insight into the biological role of radiation, as suggested by several examples of what appears to be a stress response in cells grown at doses that range from 10 to 79 times lower than background. Here, we discuss some of the technical constraints to shield cells from radiation to below-background levels, as well as different approaches used to detect and measure responses to such unusual environmental conditions. Then, we present data from Shewanella oneidensis and Deinococcus radiodurans experiments that show how two taxonomically distant bacterial species sense and respond to unnaturally low levels of radiation. In brief, we grew $S$. oneidensis and $D$. radiodurans in liquid culture at dose rates of 72.05 (control) and 0.91 (treatment) $\mathrm{nGy} \mathrm{hr}^{-1}$ (including radon) for up to $72 \mathrm{~h}$ and measured cell density and the expression of stress-related genes. Our results suggest that a stress response is triggered in the absence of normal levels of radiation.

Keywords: below-background radiation, stress response, relative gene expression, radiation biology, Shewanella oneidensis, Deinococcus radiodurans

\section{INTRODUCTION}

Ionizing radiation is a ubiquitous environmental stress that has been present throughout the life history of all organisms on earth (Karam and Leslie, 2005). It would be expected that adaptive molecular mechanisms have been selected in response to the constant exposure to this natural background radiation dose. Although this background dose varies significantly across geographical areas (Brooks, 2012), the worldwide average dose has been estimated to be $2400 \mu \mathrm{Gy} \mathrm{yr}^{-1}$ (Thorne, 2003) and only the proximity to natural and human activity-derived sources such as radioactive minerals, medical exposure or nuclear energy-related events significantly increase this number. It should be noted, however, that the background dose range has been established solely for human exposure protection purposes and that radon, one of its main components, is not relevant for bacterial models. Also, the variability of background radiation occurs only in one direction (above 
background), as there are no instances of a natural environment with the levels we have imposed in our experiment.

Ionizing radiation, such as gamma rays, deposit energy as they traverse cells causing DNA lesions, membrane damage, and the induction of pro-apoptotic genes (Todorovic et al., 2008). Ionizing radiation can cause significant increases in the concentration of intracellular reactive oxygen species, ROS, (Ghosal et al., 2005) and in bacteria, the SOS response (BrenaValle and Serment-Guerrero, 1998). These reactive species trigger the expression of enzymes that scavenge for ROS in order to protect against protein and DNA damage (Daly, 2009). Background radiation is part of the physical environment that bacteria may sense and react to in order to regulate homeostasis. If bacteria have adapted to thrive in the presence of radiation, how would they react to a significant decrease in radiation dose rate? Could cells translate the "absence" of radiation into a modulating signal to initiate a specific response? Could such a reaction be defined as a stress response? We propose that research on the biological responses to reduced-radiation environments, "from the other side of background" (Smith et al., 2011), can yield unique information that will inform both the underlying science and policy applications of radiation protection. It is necessary to consider that natural background radiation is made up of both low and high LET (Linear Energy Transfer) sources and that the latter tend to have stronger biological effects (Goodhead, 1999). However, researchers at Italy's Gran Sasso lab and Istituto Superiore di Sanita (Belli et al., 1989; Goodhead et al., 2009) have shown that the biological effects on Chinese hamster V79 cells also depends on particle type, with protons causing more cell inactivation than $\alpha$-particles at the same LET. In this report, because of the experimental set-up (shielding from the salt overburden and steel vault), the observed effects are largely due to low-LET sources.

Traditional radiation biology experiments have resulted in an impressive amount of data on the effects of acute exposure to different sources of ionizing radiation at different dose rates, all additional to natural background radiation. The study of the effects of radiation at doses below background, however, remains relatively unexplored due to the difficulties of data acquisition. The first evidence of a deleterious biological response to radiation doses lower than background was reported by Planel et al. (1987), who observed a longer generation time in Paramecium tetraurelia and a lower cell number in Synechococcus lividus cultures when these organisms were grown shielded from radiation at dose rates 17 and 6 times lower than background, respectively. Since then, experiments with other organisms have shown similar deleterious effects when exposed to below background levels of radiation, such as lower protection to mutational damage in Saccharomyces cerevisiae (Satta et al., 1995); higher sensitivity to apoptosis, higher intracellular concentration of oxidative stressrelated enzymes, and higher mutation rate induced by gamma rays (after conditioning under below background conditions) in Cricetulus griseus (Satta et al., 2002); growth rate retardation in Mus musculus L5178Y cells (Kawanishi et al., 2012), changes in the concentration of oxidative stress-related enzymes (Fratini et al., 2015), and lower cell number and/or up regulation of DNA repair and oxidative stress genes in Shewanella oneidensis and Deinococcus radiodurans (Smith et al., 2011; Castillo et al., 2015).

Below background radiation biology experiments have been hampered by the enormous technical constrains to effectively achieve radiation doses below background levels. Here, we present the Low Background Radiation Experiment (LBRE) at the Waste Isolation Pilot Plant (WIPP) in Carlsbad, NM., as an effective way to achieve an estimated 79-fold reduction in ionizing radiation dose (relative to gamma) and propose two bacterial models as reference points to study the detection of ultra-low levels of ionizing radiation and the use of gene expression analysis to describe their molecular response to the deprivation of natural levels of radiation.

\section{THE CHALLENGE OF BELOW-BACKGROUND RADIATION BIOLOGY WORK}

Shielding organisms from the different components of background radiation down to levels that are significantly below-background is not an easy task. Protection from cosmic rays and cosmic rays-derived components can be achieved at sites located deep underground or protected by a significant overburden, common for numerous physics experiments that require radiation "free" conditions, while protection from emissions derived from the decay of naturally occurring radioisotopes depends on the abundance of these elements in the immediate surroundings of the experiment. To our knowledge, only two laboratories that meet the first condition are currently running biology experiments to explore the effects of radiation deprivation on different organismal models: (1) The Laboratori Nazionali del Gran Sasso in L'Aquila, Italy, has established the "Cosmic Silence Program" to study the contribution of natural radiation to different molecular processes leading to the defense against oxidative stress (dps) using yeast, rodent, and human cells as models, at a dose rate 10 times lower than background ${ }^{1}$; and (2) the Laboratoire Souterrain de Modane, in Modane, France, who initiated the IRIS Project (Impacts of Ionizing Radiation on Life) to study the effect of ionizing radiation on the evolution of Escherichia coli exposed to chronic doses 30 times lower than their reference background ${ }^{2}$.

The LBRE laboratory, hosted by the WIPP in Carlsbad, NM., lays at a depth of $660 \mathrm{~m}$ within a $610 \mathrm{~m}$ thick halite layer (Salado formation) with an isotope composition of 29, 78, and $169 \mathrm{ppb}$ for ${ }^{238} \mathrm{U},{ }^{232} \mathrm{Th}$, and ${ }^{40} \mathrm{~K}$, respectively (Department of Energy, 1996) ${ }^{3}$. This NaCl-based salt deposit emits significantly less radiation than other rock formations like limestone and granite (Figure 1A). Additionally, part of the LBRE experiments are conducted inside a $15 \mathrm{~cm}$-thick vault made from pre-World War II, low-activity steel to further reduce exposure to radiation (Figure 1B). As the main mission of the WIPP site is the permanent disposal of low-level radioactive transuranic waste

\footnotetext{
${ }^{1}$ https://www.lngs.infn.it/en/pulex-cosmic-silence

${ }^{2} \mathrm{http} / / / \mathrm{www}$-1sm.in2p3.fr/activites/autres_activ/Bio.htm

${ }^{3}$ http://wipp.energy.gov/science/biology/biology2.html
} 


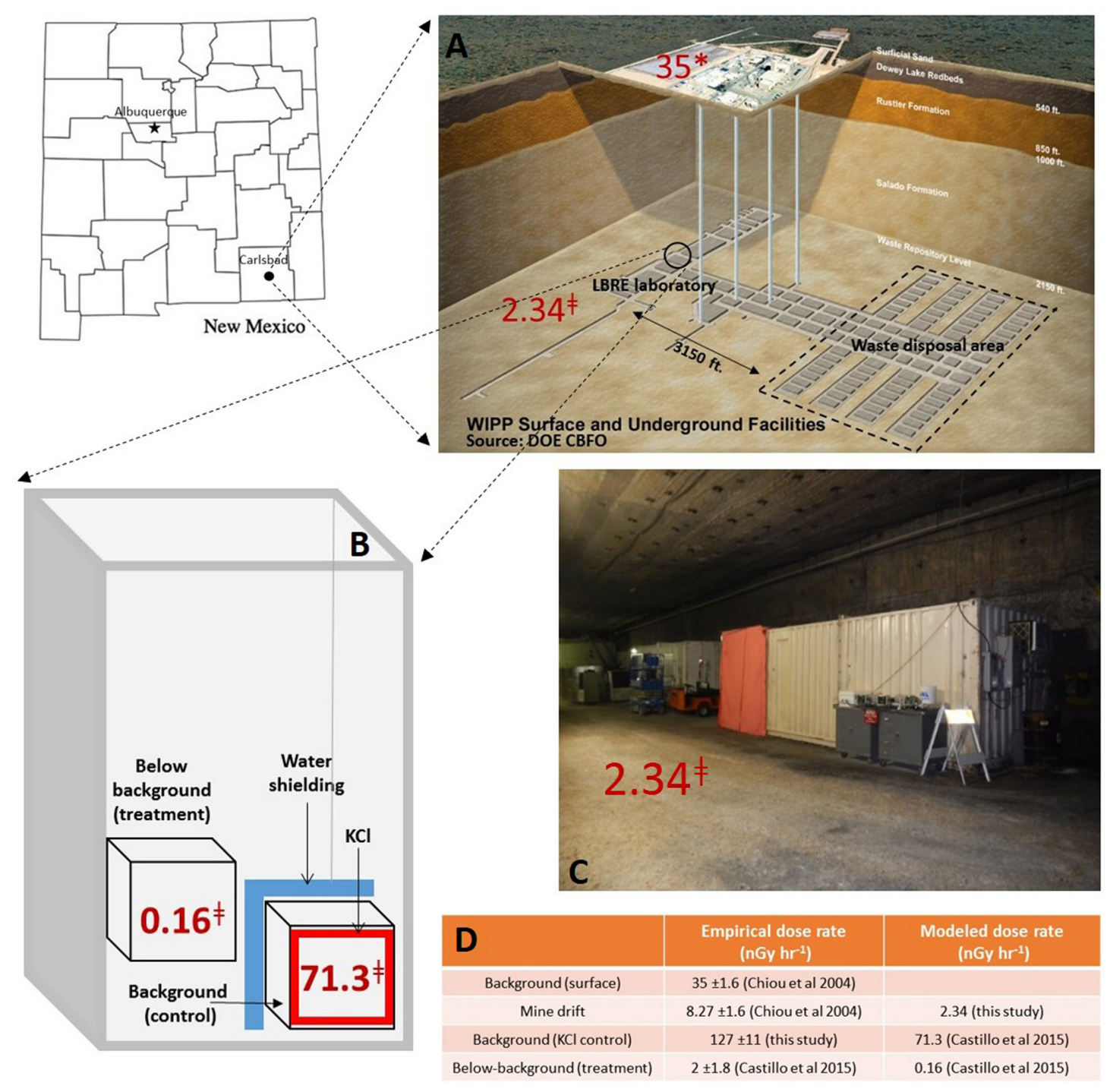

FIGURE 1 | The Low Background Radiation Experiment (LBRE) at the Waste Isolation Pilot Plant (WIPP). Numbers in red indicate dose rate in nGy hr ${ }^{-1}$. (A) The WIPP site, located $46 \mathrm{~km}$ east of Carlsbad, NM, was designed and commissioned for the permanent disposal of transuranic wastes at a depth of $650 \mathrm{~m}$ in the middle of 610-m-thick Permian salt deposit. (B) LBRE steel vault showing the location of the treatment (below-background) and control (background) incubators, with their respective estimated radiation dose (without cell media). (C) Side view of the LBRE underground laboratory in the North end drift of WIPP. Measured* using a sodium iodide detector (Chiou and Hayes, 2004), and estimated" using MCNP modeling (this study). (D) Comparison of empirical and modeled dose rates.

from the U.S. Department of Defense, access to the underground LBRE laboratory is highly regulated and in general restricted to a few hours during operation days, which in the recent past hampered the experiments in terms of sampling time points available. Starting in 2015 access was extended for up to $12 \mathrm{~h}$ per day, which allowed for a more adequate experiment and sampling regime.

In our first study, we compared the growth of $D$. radiodurans at underground vs. aboveground laboratories and observed that cultures shielded from background radiation grew slower in a $48 \mathrm{~h}$ growth period (Smith et al., 2011). Later on as we included S. oneidensis in our experiments, we also moved our background control underground (current setting), simulating a background radiation dose with $11.5 \mathrm{~kg}$ of $\mathrm{KCl}(5 \mathrm{uCi}$ of ${ }^{40} \mathrm{~K}$ ) to create an energy field with a target dose rate of $100 \mathrm{nGy} \mathrm{hr}^{-1}$ (average US background from gamma sources, Figure 1C). In order to reduce the radiation from this ${ }^{40} \mathrm{~K}$ control incubator (located at a distance of $\sim 1.5 \mathrm{~m}$ ), five $20 \mathrm{~L}$ water-filled carboys were placed outside the ${ }^{40} \mathrm{~K}$ incubator as shielding. Radiation dosimetry was initially attempted using a $\mathrm{NaI}$ detector $(3.2 \times 2.5 \mathrm{~cm} \mathrm{NaI}$ scintillator crystal, Waltham, MA, USA), but because the dose rate of interest fell below the lowest limit of detection of the instrument, Monte Carlo N-Particle (MCNP) analysis was used instead to model dose rates (see Figure 1D for comparison). Here, we show the dose rates calculated for the mine drift, the inside of the steel vault and the 
inside of both the treatment and control incubators, using the mass fraction and the specific activity for ${ }^{238} \mathrm{U},{ }^{232} \mathrm{Th},{ }^{40} \mathrm{~K}$, and ${ }^{222} \mathrm{Rn}$.

Independent of cell-type and growth media, the calculated dose rate values represent a 445-fold difference in the two experimental treatment locations (Figure 1B). However, when the contribution to dose rate from the ${ }^{40} \mathrm{~K}$ in the growth media was calculated based on the total potassium content in the components of $1.5 \mathrm{~mL}$ of TGY [24.45 and $143.77 \mu \mathrm{g} \mathrm{K}$ in tryptone and yeast extract, respectively; BD Becton Dickinson (2006)], this adds $0.75 \mathrm{nGy} \mathrm{hr}^{-1}$ to both treatments. Therefore, when both environmental and media radiation sources are considered, the cells' dose in the treatment (0.91 nGy hr-1) represents a 79-fold reduction from that in the control (72.05 nGy $\left.\mathrm{hr}^{-1}\right)$.

Shewanella oneidensis and $D$. radiodurans cultures were grown as previously described (Castillo et al., 2015). In summary, both bacteria were grown in a shielded treatment incubator and a radiation-supplemented control incubator for $24 \mathrm{~h}$ as a conditioning period, after which they were transferred into fresh broth to initiate the experiment. At this point, radiationdeprived cultures were also transferred back into the $\mathrm{KCl}$ control incubator in order to start a reciprocal control by "rescuing" cells and restoring them to normal levels of radiation. Optical density at $630 \mathrm{~nm}$ was measured at different time points $(5,8,13,24$, and 29 for S. oneidensis and 10, 24, 29,34 , and 48 for $D$. radiodurans) to quantify and compare the growth of the cultures using a Student's $t$-test $(n=12)$. In parallel, cells were sampled, treated with RNA protect (QIAGEN, Valencia, CA, USA) and kept frozen for further analysis. Total RNA was extracted using the RNeasy Mini kit (QIAGEN, Valencia, CA, USA) and used as template in RTquantitative PCR to measure the differential expression of stressrelated genes: $k a t B, \operatorname{rec} A, \operatorname{oxy} R$, lexA, dnaK, and SOA0154 for S. oneidensis and DR1998 (katB), DR0615 (oxyR), DRA0344 (lexA), recA, dnaK, DR2263 (dps), and DR1343 (gapdH) for $D$. radiodurans, using an efficiency-corrected approach (Pfaffl et al., 2002).

\section{BACTERIA RESPONSE TO RADIATION DEPRIVATION}

In our previous report (Castillo et al., 2015), we showed growth inhibition and/or the upregulation of stress-related genes in experiments with limited time points. In the experiment reported here with more site access, $S$. oneidensis cultures did not show a significant difference in growth in response to the reduced radiation dose (Figure $\mathbf{2 A}$ ), whereas $D$. radiodurans growth became inhibited at the beginning of its exponential growth phase and remained significantly different throughout the duration of the experiment (Figure 2B). As reported previously, when reciprocal controls were carried out in which radiationdeprived cells were restored to radiation-sufficient conditions, growth of $D$. radiodurans recovered and approximated the cell density of the control (dotted line, Figure 2B). However, using growth as the only endpoint to measure the effect of a particular environmental variable might be misleading since cells employ multiple physiological mechanisms in response to changing environments to maintain homeostasis. In order to circumvent this limitation, similar low-radiation dose experiments have used different approaches for a more indepth analysis of the cellular response, such as micronucleus assays (Carbone et al., 2009), enzymatic activity (Satta et al., 2002; Carbone et al., 2009; Fratini et al., 2015), mutation assays (Satta et al., 1995, 2002; Fratini et al., 2015), and differential gene expression (Castillo et al., 2015; Fratini et al., 2015). In the present study, we measured the expression of genes related to some of these types of stress, on cells collected at various time points in order to compare their differential expression.

First it should be noted the different growth kinetics of $S$. oneidensis (doubling time $=1.1 \mathrm{~h}$ ) and $D$. radiodurans (doubling time $=3 \mathrm{~h}$ ) under our culture conditions $(1.5 \mathrm{~mL}$ TGY broth, $30^{\circ} \mathrm{C}, 200 \mathrm{rpm}$ in 24 -well plate) and so the same growth stage in the two species are represented by offset times. In S. oneidensis, $33 \%$ of the genes were significantly upregulated in the minus-radiation treatment (as defined by greater than twofold change, $p<0.10$ ), whereas in $D$. radiodurans only 4.5 and $6.8 \%$ were up or downregulated, respectively (Figures $2 \mathbf{A}, \mathbf{B}$ ). The gene expression data in Figure $2 \mathrm{~A}$ shows $\mathrm{S}$. oneidensis to have upregulated five of the six stress genes tested during mid log phase and then Shewanella tapered expression back during late-log and early stationary phase. In contrast, D. radiodurans only upregulated 2 of 11 genes during a single time point at early log phase; at $24 \mathrm{~h}$ D. radiodurans also down regulated $d p s$ and $g a p d H$ (Figure 2C), and at $34 \mathrm{~h}$ downregulated $d n a K$. The upregulated genes in $S$. oneidensis are indicative of a stress response, being involved in activities such as ROS scavenging $(k a t B, o x y R)$, DNA repair $(\operatorname{rec} A$, lex $A)$, protein folding $(d n a \mathrm{~K})$, and metal efflux (SOA0154). However, D. radiodurans upregulated lexA and $d n a K$ at $24 \mathrm{~h}$ but at the same time, also downregulated two other genes involved in $d p s$ and ATP synthesis $(\mathrm{gapdH})$.

During mid-exponential phase ( $8 \mathrm{~h}$ in $S$. oneidensis), six genes related to oxidative stress response $(k a t B, o x y R)$, DNA repair (recA, lexA), protein folding (dnaK), and a putative efflux pump (SOA0154) were again significantly upregulated as we reported previously (Castillo et al., 2015). Oxidative stress and efflux pump activity was initiated and maintained during lateexponential $(13 \mathrm{~h})$ but dissipated by early stationary phase (17 h). Growth inhibition in $D$. radiodurans cultures became significant $(p<0.05)$ during mid exponential phase $(34 \mathrm{~h})$ and was maintained throughout the duration of the experiment. The difference in gene expression, however, was only observed at $24 \mathrm{~h}$ when $\operatorname{lex} A$ and $d n a K$ were significantly upregulated, suggesting an increase in DNA repair and protein folding activities, while $d p s$, and $g a p d H$ were downregulated, suggesting a diminished capacity to fend off oxidative stress (Chiancone and Ceci, 2010) and synthesize ATP, respectively. Moreover, when we transferred cells from the reduced radiation treatment to the control incubator (orange bars in Figure 2C), the regulation of the genes dissipated supporting our hypothesis that these effects were due to the absence of normal levels of radiation. 




\section{C}
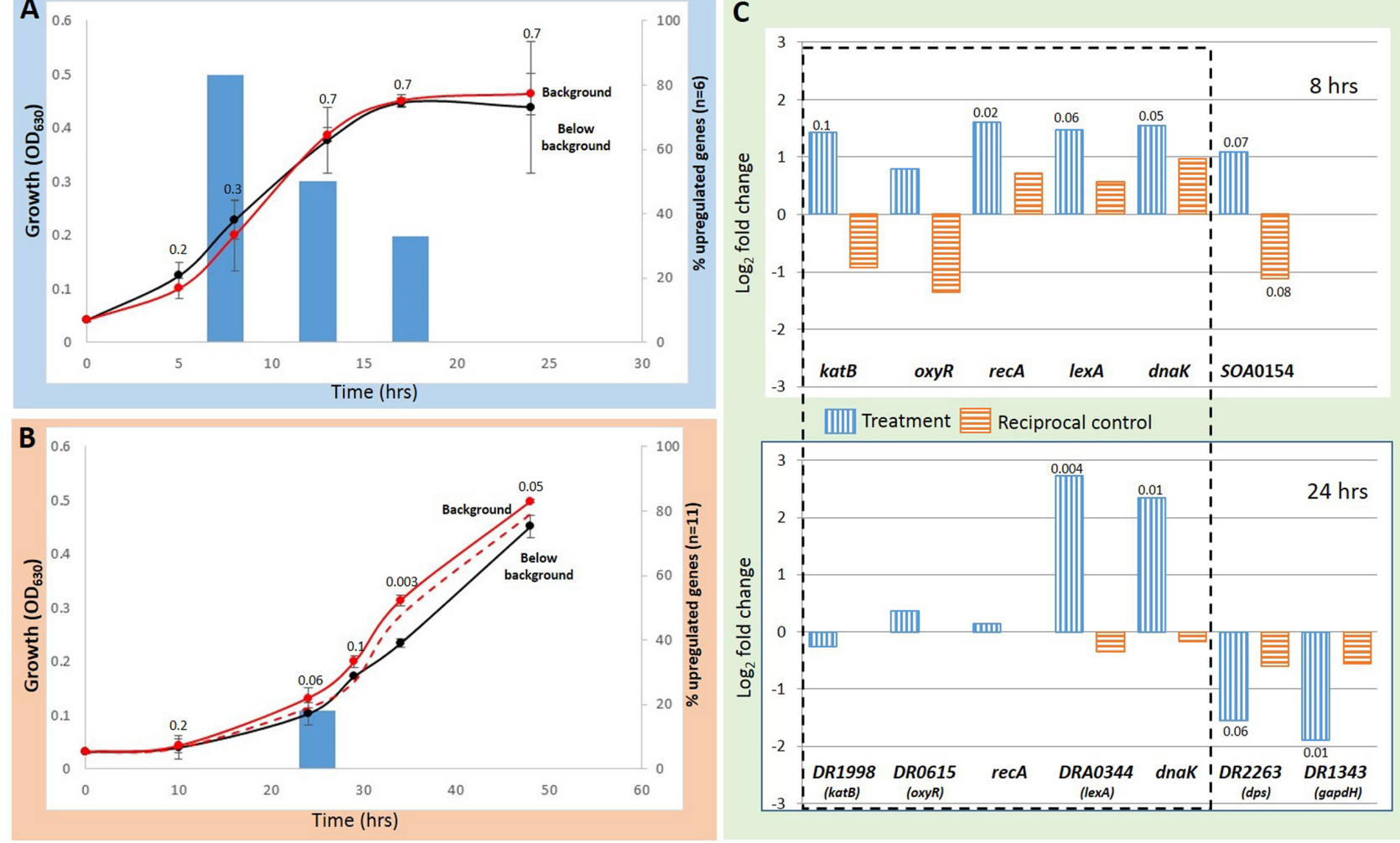

FIGURE 2 | Upregulation of stress genes in Shewanella evidently protects cells from growth inhibition by radiation deprivation. Line graphs show bacterial growth under radiation-sufficient (background) and radiation-deprived (below background) conditions with $p$-values shown above timepoints (the dotted reciprocal control was shown to be statistically the same as the background control). Both $S$. oneidensis and $D$. radiodurans were grown in $1.5 \mathrm{~mL}$ of TGY broth ( $0.5 \%$ Bacto tryptone, $0.3 \%$ yeast extract, and $0.1 \%$ glucose) in 24-wells plates, shaken at $200 \mathrm{rpm}$ and at $30^{\circ} \mathrm{C}$. Bar graphs show the percentage of genes tested that were upregulated (as defined by $>2$-fold change relative to rad-sufficient controls, $p<0.10$ ) in (A) S. oneidensis and (B) $D$. radiodurans. (C) Differential gene expression in S. oneidensis and D. radiodurans calculated using the efficiency-corrected $\triangle \mathrm{Cp}$ equation in the software tool REST2009 (Pfaffl et al., 2002). RT-qPCR on S. oneidensis RNA samples was performed with the iScript One-Step RT-PCR kit (BioRad, Hercules, CA, USA) and on D. radiodurans RNA samples with the iScript Reverse Transcription Supermix for RT-qPCR (BioRad, Hercules, CA, USA) followed by the SsoAdvanced Universal SYBR Green Supermix (BioRad, Hercules, CA, USA) according to the manufacturer's instructions. The expression of target genes was normalized using $r R N A$ (D. radiodurans) or $r R N A$ and rpoA (S. oneidensis) as reference. For D. radiodurans, the expression of groEL, sufB, DR1838 (stringent factor) and DR2422 (large conductance mechanosensitive channel) was not regulated, and therefore not shown in the figure.

\section{A BIOLOGICAL ROLE FOR BACKGROUND IONIZING RADIATION?}

We propose that $S$. oneidensis has mounted a classic stressresponse to this unusual environmental cue of the deprivation of natural levels of environmental radiation (and its growth was thus not inhibited) whereas $D$. radiodurans has not sensed this stress (and thus its growth was inhibited). A basic element of the biological stress response at the cellular level is to return the organism back to homeostasis (Kultz, 2005) and those organisms not capable of sensing and responding to stressors would be at a distinct fitness disadvantage. For example, in mammalian systems, deletion of the chemical and radiation stress sensor protein, INrf2 leads to adverse effects on cell survival (Lee et al., 2007). We propose here that the different response to the absence of radiation by our two model organisms led to a fitness cost in the organism (D. radiodurans) that did not mount an effective stress response.
The upregulation of $k a t B$ in $\mathrm{S}$. oneidensis has also been observed upon exposure to other stressors, such as $\mathrm{H}_{2} \mathrm{O}_{2}$, chromate and ionizing radiation (Brown et al., 2006; Qiu et al., 2006; Jiang et al., 2014), stressors known to induce oxidative stress. Interestingly, the upregulation of recA and lexA has also been reported as a direct effect of exposure to ionizing radiation and chromate in S. oneidensis (Brown et al., 2006; Qiu et al., 2006) and of recA in D. radiodurans after gamma irradiation (Carroll et al., 1996). The upregulation of dnaK has been associated with chromate shock in S. oneidensis (Brown et al., 2006), oxidative, heat and acid stresses in L. lactis (Smith et al., 2010), and ionic silver in E. coli (Salou-Berion et al., 2015).

Our differential gene expression analysis shows that when grown under radiation-reduced conditions, S. oneidensis increases the transcription of this suite of genes, suggesting an effective response to an increase of intracellular ROS, the repair of DNA breakage, and the need of re-folding damaged proteins, allowing for the resumption of normal growth. In the 
case of $D$. radiodurans, the upregulation of lexA and $d n a K$ at a single time point evidently was not sufficient to alleviate the deleterious effects of these insults, making the treatment and control cultures effectively different at the beginning of the exponential phase. Additionally, the upregulation of a putative metal efflux pump (SOA0154) in S. oneidensis, proposed to be involved in the detoxification of UVA-irradiated cells (Qiu et al., 2005) supports the hypothesis that 79 times below normal dose rates of radiation is perceived as a stress. Interestingly, $D$. radiodurans cultures exhibited the down regulation of $d p s$, known to contribute to DNA protection from ROS through the maintenance of metal homeostasis (Santos et al., 2015), in agreement with previous findings on the reduced transcription of this gene in the presence of $\mathrm{H}_{2} \mathrm{O}_{2}$ (Chen et al., 2008); and of $g a p d \mathrm{H}$, an essential component of glucose metabolism during glycolysis. After first documenting growth inhibition and the lack of stress-gene response in $D$. radiodurans to the absence of normal levels of radiation (Castillo et al., 2015), in the data reported here, we added $\mathrm{qPCR}$ assays for various previously reported stress-related genes, including homologs to those responsive in $S$. oneidensis, of which two were regulated, suggesting that $D$. radiodurans' response to this unusual environmental cue might be derived from different gene regulation events.

Current experiments are underway to quantify transcriptomelevel responses of these bacteria to below background radiation in an effort to identify why radiation deprivation may increase cytoplasmic ROS. Work is also underway to test the hypothesis that radiation deprivation is a stressor in C. griseus cells and in Caenorhabditis elegans in order to evaluate whether or not the ability to sense and respond to the absence of normal levels of radiation is a trait conserved in both prokaryotic and eukaryotic cells.

\section{REFERENCES}

BD (Becton Dickinson) (2006). BD Bionutrients Technical Manual, Third Edn, Vol. 28. Available at: http://www.bd.com/ds/technicalCenter/misc/br_3_2547.pdf

Belli, D., Cherubin, R., Finotto, S., Moschini, G., Sapora, O., Simone, G., et al. (1989). RBE-LET Relationship for the survival of V79 cells irradiated with low energy protons. Int. J. Radiat. Biol. 55, 93-104. doi: 10.1080/ 09553008914550101

Brena-Valle, M., and Serment-Guerrero, J. (1998). SOS induction by (-radiation in Escherichia coli strains defective in repair and/or recombination mechanisms. Mutagenesis. 13, 637-641. doi: 10.1093/mutage/13.6.637

Brooks, A. L. (2012). A history of the United States Department of Energy (DOE) Low Dose Radiation Research Program: 1999-2008. Available at: http://lowdose. energy.gov/pdf/albRoughDraft/doeHistoryComplete09262012.pdf

Brown, S. D., Thompson, M. R., VerBerkmoes, N. C., Chourey, K., Shah, M., Zhou, J., et al. (2006). Molecular dynamics of the Shewanella oneidensis response to chromate stress. Mol. Cell. Proteomics 5, 1054-1071. doi: 10.1074/ mcp.M500394-MCP200

Carbone, M. C., Pinto, M., Antonelli, F., Amicarelli, F., Balata, M., Belli, M., et al. (2009). The cosmic silence experiment: on the putative adaptive role of environmental ionizing radiation. Radiat. Environ. Biophys. 48, 189-196. doi: 10.1007/s00411-008-0208-6

\section{AUTHOR CONTRIBUTIONS}

HC and GS designed and executed the experiment, analyzed the data, wrote and edited the manuscript.

\section{FUNDING}

These results are based upon work supported by the Department of Energy Office of Environmental Management under Award Number DE-EM0002423. This report was prepared as an account of work sponsored by an agency of the United States Government. Neither the United States Government nor any agency thereof, nor any of their employees, makes any warranty, express or implied, or assumes any legal liability or responsibility for the accuracy, completeness, or usefulness of any information, apparatus, product, or process disclosed, or represents that its use would not infringe privately owned rights. Reference herein to any specific commercial product, process, or service by trade name, trademark, manufacturer, or otherwise does not necessarily constitute or imply its endorsement, recommendation, or favoring by the United States Government or any agency thereof. The views and opinions of authors expressed herein do not necessarily state or reflect those of the United States Government or any agency thereof.

\section{ACKNOWLEDGMENTS}

We would like to thank Dr. Giuseppe DiCarlo of the Gran Sasso lab (Laboratori Nazionali del Gran Sasso, L'Aquila, Italy) for his calculation representing the dose rate from the potassium in the medium used, Dr. Jeffrey Wood for the MCNP modelling and Los Alamos National Laboratory's Douglas Weaver, Brian Dozier and Shawn Otto for their technical assistance at WIPP.

Carroll, J. D., Daly, M. J., and Minton, K. W. (1996). Expression of recA in Deinococcus radiodurans. J. Bacteriol. 178, 130-135. doi: 10.1128/jb.178.1.130135.1996

Castillo, H., Schoderbek, D., Dulal, S., Escobar, G., Wood, J., Nelson, R., et al. (2015). Stress induction in the bacteria Shewanella oneidensis and Deinococcus radiodurans in response to below-background ionizing radiation. Int. J. Radiat. Biol. 91, 749-756. doi: 10.3109/09553002.2015.1062571

Chen, H., Xu, X., Zhao, Y., Tian, B., Lu, H., Yu, X., et al. (2008). A novel OxyR sensor and regulator of hydrogen peroxide stress with one cysteine residue in Deinococcus radiodurans. PLoS ONE 3:e1602. doi: 10.1371/journal.pone. 0001602

Chiancone, E., and Ceci, P. (2010). The multifaceted capacity of Dps proteins to combat bacterial stress conditions: detoxification of iron and hydrogen peroxide and DNA binding. Biochim. Biophys. Acta 1800, 798-805. doi: 10. 1016/j.bbagen.2010.01.013

Chiou, H.-C., and Hayes, R. (2004). Creating and baseline radiological standard for the Waste Isolation Pilot Plant underground. Isotopes. Environ. Health Stud. 40, 213-220. doi: 10.1080/10256010410001 678053

Daly, M. J. (2009). A new perspective on radiation resistance based on Deinococcus radiodurans. Nat. Rev. Microbiol. 7, 237-245. doi: 10.1038/nrmicro 2073 
Department of Energy (1996). Title 40 CFR part 191 Compliance Certification Application. Carlsbad, NM: United States Department of Energy Waste Isolation Pilot Plant.

Fratini, E., Carbone, C., Capece, D., Esposito, G., Simone, G., Tabocchini, M. A., et al. (2015). Low-radiation environment affects the development of protection mechanisms in V79 cells. Radiat. Environ. Biophys. 54, 183-194. doi: 10.1007/ s00411-015-0587-4

Ghosal, D., Omelchenko, M. V., Gaidamakova, E. K., Matrosova, V. Y., Vasilenko, A., Venkateswaran, A., et al. (2005). How radiation kills cells: survival of Deinococcus radiodurans and Shewanella oneidensis under oxidative stress. FEMS Microbiol. Rev. 29, 361-375. doi: 10.1016/j.fmrre.2004.12.007

Goodhead, D., Belli, M., Mill, A. J., Bance, D. A., Allens, L. A., Hall, S. C., et al. (2009). Direct Comparison between protons and alpha-particles of the same LET: I. Irradiation methods and inactivation of asynchronous V79, HeLa and C3H 10T1/2 cells. Int. J. Radiat. Biol. 61, 611-624. doi: 10.1080/ 09553009214551421

Goodhead, D. T. (1999). Mechanisms for the biological effectiveness of high-LET radiation. J. Radiat. Res. 40, 1-13. doi: 10.1269/jrr.40.S1

Jiang, Y., Dong, Y., Luo, Q., Li, N., Wu, G., and Gao, H. (2014). Protection from oxidative stress relies mainly on derepression of OxyR-dependent and Dps in Shewanella oneidensis. J. Bacteriol. 196, 445-458. doi: 10.1128/JB.01077-13

Karam, P. A., and Leslie, S. A. (2005). Changes in terrestrial natural radiation levels over the history of life. Radioact. Environ. 7, 107-117. doi: 10.1097/HP. 0b013e3182118094

Kawanishi, M., Okuyama, K., Shiraishi, K., Matsuda, Y., Taniguchi, R., Shiomi, N., et al. (2012). Growth retardation of paramecium and mouse cells by shielding them from background radiation. J. Radiat. Res 53, 404-410. doi: 10.1269/jrr. 11145

Kultz, D. (2005). Molecular and evolutionary basis of the cellular stress response. Annu. Rev. Physiol. 67, 225-257. doi: 10.1146/annurev.physiol.67.040403. 103635

Lee, O.-H., Jain, A. J., Papusha, V., and Jaiswal, A. K. (2007). An auto-regulatory loop between stress sensors INrf2 and Nrf2 controls their cellular abundance. J. Biol. Chem. 282, 36412-36420. doi: 10.1074/jbc.M706517200

Pfaffl, M. W., Horgan, G. W., and Dempfle, L. (2002). Relative expression software tool REST@ for group-wise comparison and statistical analysis of relative expression results in real-time PCR. Nucleic Acids Res. 30, 1-10. doi: 10.1093/ nar/30.9.e36

Planel, H., Soleilhavoup, J. P., Tizador, R., Richoilley, G., Conter, A., Croute, F., et al. (1987). Influence on cell proliferation of background radiation or exposure to very low, chronic $\gamma$ radiation. Health Phys. 52, 571-578. doi: 10.1097/00004032198705000-00007

Qiu, X., Daly, M. J., Vasilenko, A., Omelchenko, M. V., Gaidamakova, E. K., $\mathrm{Wu}$, J., et al. (2006). Transcriptome analysis applied to survival of Shewanella oneidensis MR-1 exposed to ionizing radiation. J. Bacteriol. 188, 1199-1204. doi: 10.1128/JB.188.3.1199-1204.2006

Qiu, X., Sundin, G. W., Wu, L., Zhou, J., and Tiedje, J. M. (2005). Comparative analysis of differentially expressed genes in Shewanella oneidensis MR-1 following exposure to UVC. UVB and UVA radiation. J. Bacteriol. 187, 3556-3564. doi: 10.1128/JB.187.10.3556-3564.2005

Salou-Berion, C., Gonzalez, I., Enjalbert, B., Audinot, J.-N., Fourquaux, I., Jamme, F., et al. (2015). Escherichia coli under ionic silver stress: and integrative approach to explore transcriptional, physiological and biochemical responses. PLoS ONE 10:e0145748. doi: 10.1371/journal.pone. 0145748

Santos, S. P., Mitchell, E. P., Franquelim, H. G., Castanho, M. A. R. B., Abreu, I. A., and Romao, C. V. (2015). Dps from Deinococcus radiodurans: oligomeric forms of Dps1 with distinct cellular functions and Dps2 involved in metal storage. FEBS J. 282, 4307-4327. doi: 10.1111/febs. 13420

Satta, L., Antonelli, F., Belli, M., Sapora, O., Simone, G., Sorrentino, E., et al. (2002). Influence of a low background radiation environment on biochemical and biological responses in V79 cells. Radiat. Environ. Biophys. 41, 217-224.

Satta, L., Augusti-Tocco, G., Ceccarelli, R., Esposito, A., Fiore, M., Paggi, P., et al. (1995). Low environmental radiation background impairs biological defence of the yeast Saccharomyces cerevisiae to chemical radiomimetic agents. Mutat. Res. 347, 129-133. doi: 10.1016/0165-7992(95)00031-3

Smith, G. B., Grof, Y., Navarrette, A., and Guilmette, R. A. (2011). Exploring biological effects of low level radiation from the other side of background. Health Phys. 100, 263-265. doi: 10.1097/HP.0b013e318208cd44

Smith, W. M., Dykes, G. A., Soomro, A. H., and Turner, M. S. (2010). Molecular mechanisms of stress resistance in Lactococcus lactis. Microbiol. Mol. Biol. Rev. $80,837-890$.

Thorne, M. C. (2003). Background radiation: natural and man-made. J. Radiol. Prot. 23, 29-42. doi: 10.1088/0952-4746/23/1/302

Todorovic, D., Petrovic, I., Todorovic, M., Cuttone, G., and Ristic-Fira, A. (2008). Early effects of gamma rays and protons on human melanoma cell viability and morphology. J. Microsc. 232, 517-521.

Conflict of Interest Statement: The authors declare that the research was conducted in the absence of any commercial or financial relationships that could be construed as a potential conflict of interest.

Copyright (c) 2017 Castillo and Smith. This is an open-access article distributed under the terms of the Creative Commons Attribution License (CC BY). The use, distribution or reproduction in other forums is permitted, provided the original author(s) or licensor are credited and that the original publication in this journal is cited, in accordance with accepted academic practice. No use, distribution or reproduction is permitted which does not comply with these terms. 